\title{
Peritumoral SPARC expression and patient outcome with resectable intrahepatic cholangiocarcinoma
}

\author{
Chi-Tung Cheng',* \\ Yin-Yi Chu',* \\ Chun-Nan Yeh' \\ Shih-Chiang Huang ${ }^{3}$ \\ Ming Huang Chen ${ }^{4}$ \\ Shang-Yu Wang' \\ Chun-Yi Tsai' \\ Kun-Chun Chiang ${ }^{5}$ \\ Yen-Yang Chen ${ }^{6,7}$ \\ Ming-Chun $\mathrm{Ma}^{6,7}$ \\ Chien-Ting Liu ${ }^{6,7}$ \\ Tsung-Wen Chen' \\ Ta-Sen Yeh'
}

'Department of Surgery, ${ }^{2}$ Department of Gastroenterology and Hepatology,

${ }^{3}$ Department of Pathology, Chang

Gung Memorial Hospital, Chang Gung

University, Taoyuan, Taiwan; ${ }^{4}$ Division

of Hematology and Oncology,

Department of Medicine, Taipei

Veterans General Hospital, Taipei,

Taiwan; ${ }^{5}$ Department of Surgery,

Chang Gung Memorial Hospital,

Chang Gung University, Keelung,

Taiwan; ${ }^{6}$ Division of Hematology and Oncology, Department of Internal Medicine, Kaohsiung Chang Gung Memorial Hospital, Kaohsiung, Taiwan;

${ }^{7}$ Chang Gung University, Taoyuan,

Taiwan

*These authors contributed equally to this work

Correspondence: Chun-Nan Yeh Department of Surgery, Chang Gung Memorial Hospital, Chang Gung University, 5 Fu-Hsing Street, Kwei-Shan, Taoyuan, Taiwan

Tel +886 $3328 \quad 1200$ ext 3219

Fax +88633285818

Email yehchunnan@gmail.com
This article was published in the following Dove Press journal:

OncoTargets and Therapy

28 July 2015

Number of times this article has been viewed

Background and objectives: Cholangiocarcinoma (CCA) affects thousands worldwide with increasing incidence. SPARC (secreted protein acidic and rich in cysteine) plays an important role in cellular matrix interactions, wound repair, and cellular migration, and has been reported to prevent malignancy from growth. SPARC undergoes epigenetic silencing in pancreatic malignancy, but is frequently expressed by stromal fibroblasts adjacent to infiltrating pancreatic adenocarcinomas. CCA is also a desmoplastic tumor, similar to pancreatic adenocarcinoma. SPARC's clinical influence on clinicopathological characteristics of mass-forming (MF)-CCA still remains unclear. In this study, we evaluate the expression of SPARC in tumor and stromal tissue to clarity its relation with prognosis.

Methods: Seventy-eight MF-CCA patients who underwent hepatectomy with curative intent were enrolled for an immunohistochemical study of SPARC. The expression of immunostaining of SPARC was characterized for both tumor and stromal tissues. We conducted survival analysis with 16 clinicopathological variables. The overall survival (OS) was analyzed by Kaplan-Meier analysis and Cox proportional hazards regression modeling.

Results: Thirty-three men and 45 women with MF-CCA were studied. Within total 78 subjects, $12(15.4 \%)$ were classified as tumor negative/stroma negative, 37 (47.4\%) as tumor positive/stroma negative, four $(5.1 \%)$ as tumor negative/stroma positive, and $25(32.1 \%)$ as tumor positive/stroma positive. With a median follow-up of 13.6 months, the 5-year OS was $14.9 \%$. Cox proportional hazard analysis revealed that SPARC tumor positive and stromal negative immunostaining and curative hepatectomy predicted favorable OS in patients with MF-CCA after hepatectomy.

Conclusion: MF-CCA patients with SPARC tumor positive and stromal negative expression may have favorable OS rates after curative hepatectomy.

Keywords: SPARC, mass-forming cholangiocarcinoma, prognosis, predicting factors

\section{Synopsis}

SPARC tumor positive and stromal negative expression and curative resection independently predicted favorable OS rates in MF-CCA after surgery.

\section{Introduction}

Cholangiocarcinoma (CCA) is a relatively rare malignancy of the hepatobiliary system; however, the incidence and mortality of CCA are increasing worldwide. ${ }^{1-3}$ Intrahepatic CCA is the second most common hepatic malignancy, accounting for $10 \%-15 \%$ of all primary liver malignancies, ${ }^{4}$ including mass-forming (MF), periductal-infiltrating, and intraductal papillary types grossly. ${ }^{5}$ The MF type comprised the most common subtype of CCA with high possibility of recurrence in the remnant liver even with curative resection. 
Clinically, CCA is still challenging nowadays and usually presents at advanced stage. Curative resection with uninvolved surgical margins is treatment of choice, but recurrence is common. ${ }^{6}$ Although liver transplantation has provided an alternative instead of hepatectomy, frequent recurrence following transplantation limits the application of this alternative. $^{7}$ The biological behavior of the CCA and its early recurrence limit the efficacy of surgery with unsatisfactory clinical outcome. ${ }^{6,8-12}$ Furthermore, radiotherapy or chemotherapy does not markedly improve long-term survival. ${ }^{10,12}$

Intrahepatic CCA is a desmoplastic tumor that is similar to pancreatic adenocarcinoma. Utispan et al had reported the gene expression profile of CCA-derived fibroblasts revealing the upregulated SPARC (secreted protein acidic and rich in cysteine) or osteonectin/BM40 gene, compared with fibroblasts from the liver without malignancy. ${ }^{13}$ Seol et al used DNA microarrays to analyze and compare the gene expression between CCA cell lines and normal biliary cells. The SPARC gene is overexpressed by both CCA cell lines and human tissue samples. ${ }^{14}$

SPARC is a calcium-binding protein interacting with the extracellular matrix. SPARC influences cell migration, ${ }^{15}$ proliferation, angiogenesis, matrix cell adhesion, and tissue remodeling. SPARC is an indicator of activated fibroblasts. ${ }^{16}$ The cell growth inhibition from SPARC is demonstrated by SPARC-knockout mice with faster tumor growing than mice expressing SPARC. ${ }^{17,18}$ Its expression is often unseen in pancreatic cancer cells through aberrant DNA methylation, but juxtatumoral fibroblasts often express SPARC. ${ }^{19}$ The phenomenon implicates the SPARC's complicated role in tumorigenesis. Increased SPARC expression has been described in malignancies from different origins, including colon, esophagus, ${ }^{20}$ pancreas, ${ }^{19}$ breast, ${ }^{21}$ lung, ${ }^{22}$ brain, urinary bladder, ${ }^{23}$ kidney, ${ }^{24}$ and melanoma. SPARC may help facilitate metastasis of cancer cells from prostate and breast in vitro, ${ }^{25,26}$ explaining SPARC overexpression was associated with poor prognosis. ${ }^{20,21,23,27,28}$ Although few researches ever specified the expression of SPARC in cancer cells or stroma, its impact on CCA was still lacking. ${ }^{29,30}$

In this study, we evaluated the prognostic significance of SPARC expression in both CCA cancer cells and its stroma in 78 patients after curative hepatectomy for intrahepatic CCA.

\section{Materials and methods}

\section{Demographic features of 78 patients with MF-CCA}

From the CCA registration of the Department of Surgery of Chang Gung Memorial Hospital, 78 MF-CCA patients undergoing hepatectomy between 1989 and 2006 were selected for the current study based on the availability of adequate amount of tumor cells. Intrahepatic CCA was defined as malignant tumor arising from second order or more distal orders of the intrahepatic ducts. Cancers from all the subjects were further classified into three different macroscopic appearances: MF-CCA, periductal-infiltrating CCA, and intraductal papillary CCA. Curative resection was defined as a resection with negative margin microscopically. Surgical mortality was defined as death of patients within the 1 st month after hepatectomy. Laboratory tests were conducted on the day before the surgery. Serum carbohydrate antigen 19-9 (CA 19-9) and carcinoembryonic antigen (CEA) were measured by radioimmunoassay. The lesions were preoperatively assessed by abdominal ultrasonography (US), endoscopic retrograde cholangiopancreatography, percutaneous transhepatic cholangiography, computed tomography, magnetic resonance cholangiopancreatography, and hepatic arteriography. The pathologic stage of tumor was defined according to the pathological tumor node metastasis classification proposed by the American Joint Committee on Cancer, 6th edition. Adjuvant chemotherapy was intravenously administered with 5-fluorouracil-based regimens for selected patients. Institutional Review Board of the Chang Gung Memorial Hospital approved this study. All the patients were informed and signed informed consent before taking part in the study.

\section{Immunohistochemical study of SPARC in $78 \mathrm{MF}-\mathrm{CCA}$}

Hematoxylin and eosin-stained slides from each patient were reviewed. Specimens of hepatectomy from all MF-CCA patients had been fixed in formalin and embedded in paraffin. A $4 \mu \mathrm{m}$ section of each specimen was stained for stratifin. The primary antibody against SPARC (clone 1B2, mouse anti-SPARC monoclonal antibody, ab117561; Abcam, Cambridge, UK) was diluted (1:30) and added to the slides that were then incubated overnight at $4^{\circ} \mathrm{C}$. The slides were then washed three times for 5 minutes in Tris-buffered saline with Tween-20 before visualization with the Dako labeled streptavidin-biotin2 (LSAB2) system, peroxidase (Dako A/S, No K0675; Dako Denmark A/S, Glostrup, Denmark). Control slides were incubated with a secondary antibody only. After washing three times in Tris-buffered saline with Tween-20 for 5 minutes each, the slides were mounted. Similar to the previous studies published by Sato et a ${ }^{19}$ immunostaining of SPARC was scored by one of the authors blinded to the outcome (C-NY, S-CH [pathologist]). SPARC immunostaining 
was stratified as negative when the intensity was absent to weak (+) and the extent was less than $10 \%$. Immunolabeling was positive if the intensity was moderate $(++)$ to strong $(+++)$ and the extent was $\geq 10 \%$. SPARC was categorized as positive or negative for both the carcinoma and the normal juxtatumoral tissue of the liver: tumor negative/stroma negative, tumor positive/stroma negative, tumor negative/stroma positive, and tumor positive/stroma positive.

\section{Follow-up study}

The follow-up evaluation in clinical office included physical examinations and blood chemistry tests regularly. Besides, serum levels of CEA and CA 19-9 were checked and remnant liver was examined by US every 3 months. When a suspected finding was revealed by US or elevated levels of tumor markers, abdominal computed tomography or magnetic resonance cholangiopancreatography was arranged for further survey. Moreover, when patients complained of bone pain, bone scans were arranged to detect metastatic bone lesion. If any of the aforementioned examinations revealed recurrence, the patient was hospitalized for a comprehensive and detailed assessment, including angiographic evaluation or magnetic resonance imaging. The management for recurrence included surgery, systemic chemotherapy, external beam radiotherapy, intraluminal radiotherapy, interventional radiological therapy, and hospice care.

\section{Statistical analysis}

The overall survival (OS) was evaluated with Kaplan-Meier method. Sixteen clinicopathological variables were considered for initial univariable analysis by the log-rank test. The Cox proportional hazards model was applied for multivariate regression. The statistical software SPSS for Windows (SPSS version 17.0; SPSS Inc., Chicago, IL, USA) was used for the statistical analysis. A value of $P \leq 0.05$ derived from two-tailed test was considered statistically significant.

\section{Results}

\section{SPARC staining of human MF-CCA specimens in relation to demographic features}

In the stroma, SPARC expression was mostly obviously seen in the cytoplasm of peritumoral fibroblasts. The extracellular matrix and other inflammatory cells (macrophages and lymphocytes) did not demonstrate this phenomenon. Fibroblast SPARC expression was most prominent in cells nearby infiltrating cancer cells and was usually weak, or even absent, in the stroma far from cancer cells. Within total 78 subjects,
$12(15.4 \%)$ were classified as tumor negative/stroma negative, $37(47.4 \%)$ as tumor positive/stroma negative, four (5.1\%) as tumor negative/stroma positive, and 25 (32.1\%) as tumor positive/stroma positive (Figure 1). Parameters associated with overall mortality were compared for all the 78 patients according to their SPARC status (Table 1). SPARC patterns were similar irrespective of sex, age, tumor size, nodal status, margin status, and differentiated status.

\section{Analyses for survival and prognosis for MF-CCA patients with hepatectomy}

Seventy-eight MF-CCA patients (33 men and 45 women) with a median age of 59.5 years (range: $29-83$ years) received regular follow-up until death after surgery. No patient was excluded from the survival analysis because no surgical mortality occurred in this study (surgical mortality rate: $0 \%$ [0/78]). A total of $78 \mathrm{MF}-\mathrm{CCA}$ patients who had undergone hepatectomy were enrolled in the survival analysis. The median follow-up was 13.6 months (from 1.4 months to 94.1 months). The OS rates at 1 year, 3 years, and 5 years were $55.1 \%, 22.9 \%$, and $14.9 \%$, respectively.

Log-rank test identified the following factors as favorable influences on the OS rate of 78 MF-CCA patients who had undergone hepatectomy: absence of symptoms, low preoperative alkaline phosphatase (ALK-P) and CEA level, size of tumor $<5 \mathrm{~cm}$, SPARC expression tumor positive and stromal negative, and negative surgical margin status (Table 2). However, multivariate Cox proportional hazard analysis demonstrated that SPARC expression tumor positive and stromal negative and curative hepatectomy independently predicted a favorable OS rate for MF-CCA patients after hepatectomy (Table 3, Figure 2A and B).

\section{Discussion}

This study focused on the value of SPARC for OS prediction in MF-CCA patients who had undergone hepatectomy. Univariate and multivariate analyses were applied to explore the relationship between OS of 78 MF-CCA patients after hepatectomy and 16 clinicopathological factors with relevance, including the SPARC staining status.

Patients who had been diagnosed with MF-CCA asymptomatically and incidentally had a relative favorable survival, but only demonstrated by univariate survival analysis. Clinically, early detection is still challenging because the patients usually do not present without symptoms due to the fact that the symptoms are vague until the disease is quite advanced. That is the reason why more than half of the MF-CCA patients presented with a tumor size $>5 \mathrm{~cm}$ 

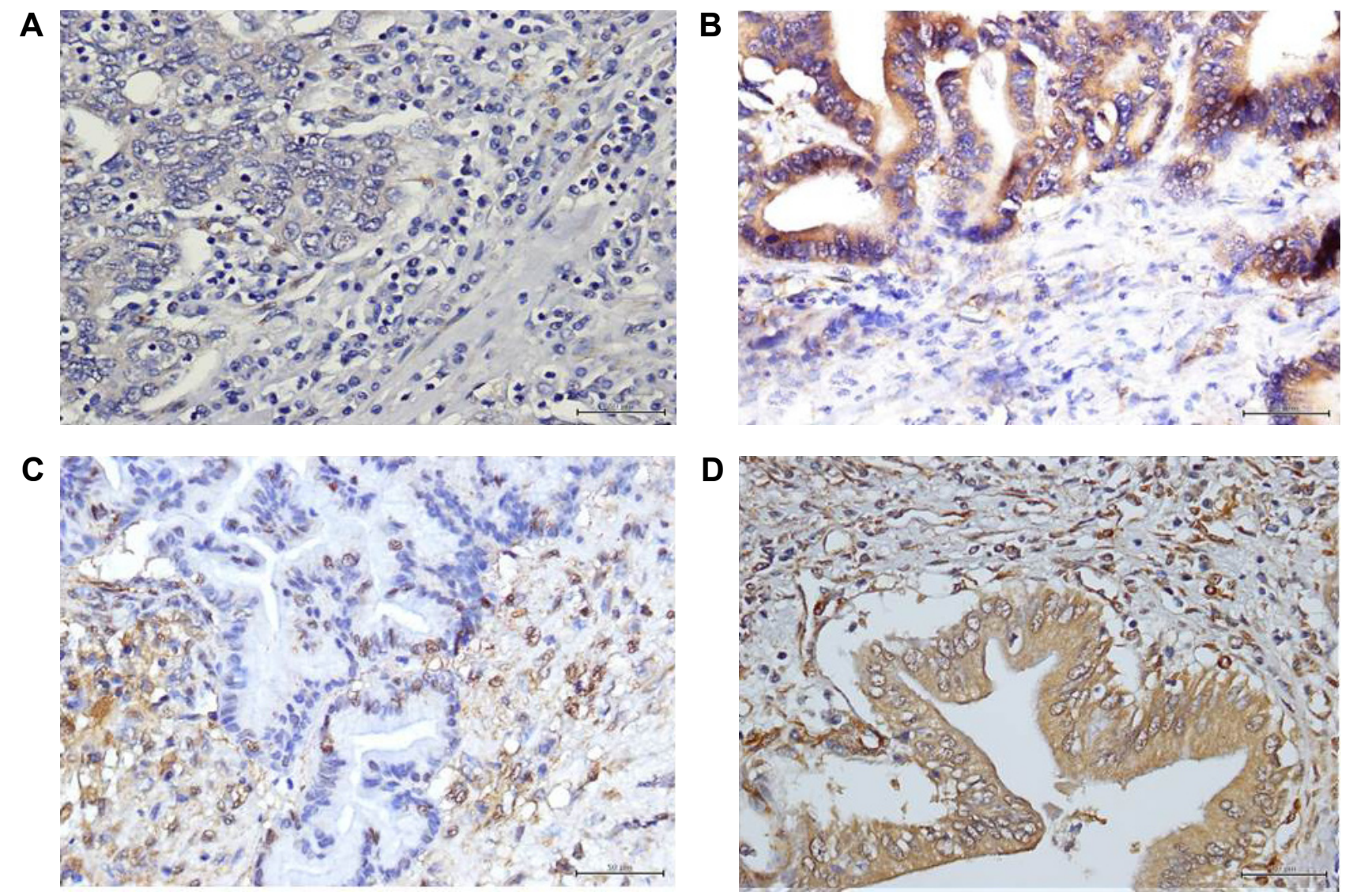

Figure I Patterns of immunohistochemical expression of SPARC in MF-CCA.

Notes: (A) Cancer SPARC expression negative, stromal expression negative; (B) cancer SPARC expression positive, stromal expression negative; (C) cancer SPARC expression negative, stromal expression positive; and (D) cancer SPARC expression positive, stromal expression positive $(\times 400)$.

Abbreviations: SPARC, secreted protein acidic and rich in cysteine; MF-CCA, mass-forming cholangiocarcinoma.

clinically. Therefore, searching for a novel tumor marker, especially focusing on patients with high risk, for the early and vigilant detection of CCA is imperative.

Elevated ALK-P level negatively impacts on long-term OS and disease-free survival in both cirrhotic and noncirrhotic patients as well as in patients with hepatocellular carcinoma larger than $10 \mathrm{~cm}$ in diameter. ${ }^{31-34}$ Similarly, our current study also revealed that elevated ALK-P levels impacted negatively on OS following hepatectomy for MF-CCA, as measured by univariate survival analysis. This fact may implicate the existence of liver disease and bile duct obstruction. Furthermore, high preoperative ALK-P level may be correlated with dismal outcome after hepatectomy for metastatic diseases. ${ }^{35}$

Diagnostic adjuncts for CCA, for example, serum markers, are useful for clinical practice. CA 19-9 and CEA levels had been reported useful for diagnosing CCA in primary sclerosing cholangitis. ${ }^{36}$ The serum level of CA 19-9 is an indicator of tumor burden, and the researchers suggested that elevated CA 19-9 in patients with CCA might be complicated with unresectable disease. ${ }^{36}$ Okabayashi et al reported that elevated serum tumor markers, which include CEA and CA 19-9, were predictive of an unfavorable outcome. ${ }^{37}$ Our current study also showed that CEA is a prognostic predictor for MF-CCA patients after hepatectomy. However, it presented no statistical significance in multivariate analysis.

Hepatic resection is the standard treatment for CCA. ${ }^{38}$ Similar to the findings demonstrated in our previous report, MF-CCA patients without curative resection were exposed to increased possibility of reducing the long-term OS rate by 2.57 times according to Cox proportional hazard analysis. ${ }^{39}$ This fact emphasizes that curative hepatic resection is essential for long-term OS of MF-CCA patients.

Our study revealed that SPARC expression in peritumoral fibroblasts is a strong indicator of poor prognosis in patients with MF-CCA after curative intent hepatectomy $(P=0.024)$, patients whose CCA stroma with positive staining for SPARC had a median survival of 8.25 months compared with 17.16 months for those whose stroma was 
Table I Clinicopathological features compared between MF-CCA patients with SPARC tumor positive and stromal negative expression and other patients

\begin{tabular}{|c|c|c|c|}
\hline & $\begin{array}{l}\text { SPARC tumor positive } \\
\text { and stromal negative } \\
\text { expression }(n=37)\end{array}$ & $\begin{array}{l}\text { Others } \\
(n=4 I)\end{array}$ & $P$ \\
\hline Age (years) & $59.98 \pm 11.33$ & $59.54 \pm 12.68$ & 0.872 \\
\hline \multicolumn{4}{|l|}{ Sex } \\
\hline Male & I 8 (54.5\%) & $15(45.5 \%)$ & \multirow[t]{2}{*}{0.282} \\
\hline Female & $19(42.2 \%)$ & $26(57.8 \%)$ & \\
\hline \multicolumn{4}{|l|}{ Symptoms } \\
\hline Negative & $8(66.7 \%)$ & 4 (33.3\%) & \multirow[t]{2}{*}{0.147} \\
\hline Positive & $29(43.9 \%)$ & $37(56.1 \%)$ & \\
\hline \multicolumn{4}{|l|}{ AST (IU/L) } \\
\hline$\leqq 34$ & $20(51.3 \%)$ & 19 (48.7\%) & \multirow[t]{2}{*}{0.565} \\
\hline$>34$ & $17(44.7 \%)$ & $2 \mathrm{I}(55.3 \%)$ & \\
\hline \multicolumn{4}{|l|}{$\mathrm{ALT}(\mathrm{U} / \mathrm{L})$} \\
\hline$\leqq 36$ & $19(47.5 \%)$ & 21 (52.5\%) & \multirow[t]{2}{*}{0.540} \\
\hline$>36$ & $17(54.8 \%)$ & 14 (45.2\%) & \\
\hline \multicolumn{4}{|l|}{ ALP (U/L) } \\
\hline$\leqq 94$ & $12(52.2 \%)$ & II (47.8\%) & \multirow[t]{2}{*}{0.525} \\
\hline$>94$ & $23(44.2 \%)$ & $29(55.8 \%)$ & \\
\hline \multicolumn{4}{|c|}{ Bilirubin (total) (mg/dL) } \\
\hline$\leqq 1.3$ & $33(51.6 \%)$ & 31 (48.4\%) & \multirow[t]{2}{*}{0.119} \\
\hline$>1.3$ & $4(28.6 \%)$ & $10(71.4 \%)$ & \\
\hline \multicolumn{4}{|c|}{ Albumin $(\mathrm{g} / \mathrm{dL})$} \\
\hline$\leqq 3.5$ & 9 (40.9\%) & 13 (59.1\%) & \multirow[t]{2}{*}{0.528} \\
\hline$>3.5$ & $24(49.0 \%)$ & $25(51.0 \%)$ & \\
\hline \multicolumn{4}{|c|}{ Serum CEA (ng/mL) } \\
\hline$\leqq 5$ & $9(36.0 \%)$ & $16(64.0 \%)$ & \multirow[t]{2}{*}{0.160} \\
\hline$>5$ & $17(54.8 \%)$ & 14 (45.2\%) & \\
\hline \multicolumn{4}{|l|}{ Stage } \\
\hline 1 & 14 (37.8\%) & II (26.8\%) & \multirow[t]{4}{*}{0.405} \\
\hline II & I (2.7\%) & $5(12.2 \%)$ & \\
\hline III & $19(51.4 \%)$ & $21(51.2 \%)$ & \\
\hline IV & 3 (8.1\%) & $4(9.8 \%)$ & \\
\hline \multicolumn{4}{|l|}{ Size $(\mathrm{cm})$} \\
\hline$\leqq 5$ & 14 (43.8\%) & 18 (56.3\%) & \multirow[t]{2}{*}{0.404} \\
\hline$>5$ & $23(53.5 \%)$ & 20 (46.5\%) & \\
\hline \multicolumn{4}{|l|}{ Lymph node } \\
\hline Negative & $22(46.8 \%)$ & 25 (53.2\%) & \multirow[t]{2}{*}{0.901} \\
\hline Positive & 14 (48.3\%) & 15 (51.7\%) & \\
\hline Differentiate & & & \\
\hline Well & $0(00.0 \%)$ & $2(100.0 \%)$ & 0.256 \\
\hline Moderate & $19(46.3 \%)$ & $22(53.7 \%)$ & \\
\hline Poorly & $16(48.5 \%)$ & 17 (5I.5\%) & \\
\hline Others & $2(100.0 \%)$ & 0 (00.0\%) & \\
\hline Margin & & & \\
\hline Negative & 27 (50.0\%) & 27 (50.0\%) & 0.496 \\
\hline Positive & 10 (4I.7\%) & 14 (58.3\%) & \\
\hline Post-op chen & herapy & & \\
\hline Without & $12(36.4 \%)$ & $2 \mathrm{I}(63.6 \%)$ & 0.094 \\
\hline With & $25(55.6 \%)$ & 20 (44.4\%) & \\
\hline Post-op radic & rapy & & \\
\hline Without & $34(50.0 \%)$ & 34 (50.0\%) & 0.317 \\
\hline With & $3(30.0 \%)$ & 7 (70.0\%) & \\
\hline
\end{tabular}

Abbreviations: MF-CCA, mass-forming cholangiocarcinoma; SPARC, secreted protein acidic and rich in cysteine; AST, aspartate aminotransferase; IU, international unit; ALT, alanine aminotransferase; ALP, alkaline phosphatase; CEA, carcinoembryonic antigen; op, operation. not noted with expression of SPARC. Although bias is inevitable when it comes to retrospective studies, our study is fortified by the fact that some patients were followed over a relatively long clinical course (94.1 months). The point estimates in the multivariate Cox proportional hazards models suggest that stromal SPARC expression may be a practical biomarker in relation to outcome and an equivalent of common clinical parameters, such as positive surgical margins. Although SPARC status was not associated with any clinicopathological feature, SPARC remained an independent factor for outcome prediction in the multivariate analysis.

In our study, we only enrolled patients with surgically curable MF-CCA. Whether this result can be applied to patients with unresectable disease is unknown. According to our result, SPARC expression might be used as an indicator for risk stratification before surgical resection. Until better target therapies specific to SPARC are available, surgical resection should be for all patients with resectable MF-CCA. Furthermore, a tru-cut biopsy is necessary for the evaluation of stromal versus tumor cell SPARC expression. Although biopsy is technically feasible and can increase diagnostic information, ${ }^{40}$ well-conducted studies are necessary to validate its safety and application.

In addition to aforementioned, our study also suggested that the neighboring stroma may be important for the phenotypic behavior of a malignancy. West et $\mathrm{a}^{41}$ reported that the host stromal response varies markedly among malignancies. Compared with the gene expression profiles in solitary fibrous tumors and desmoid-type fibromatosis, they suggested that breast cancer may induce distinct stromal reactions. Koukourakis et $\mathrm{al}^{42}$ found a strong association between stromal SPARC expression and prognosis in nonsmall cell lung cancer patients. Jones et $\mathrm{al}^{43}$ demonstrated that in breast cancers, SPARC expression in myoepithelial cells compared with luminal cells conferred a worse prognosis, although only approximately $5 \%$ of breast cancers expressed SPARC.

The mechanism by which stromal SPARC expression leads to a worse prognosis needed to be further clarified. We did not find a correlation between intratumoral SPARC expression and stromal SPARC expression. However, we believe that peritumoral fibroblast SPARC expression is an indicator of activated fibroblasts. We presume that activated peritumoral fibroblasts is a prelude to poor prognosis by unknown mechanisms.

Previous reports have also demonstrated that a woundlike reaction of fibroblasts indicated poor outcomes in 
Table 2 Univariate analysis of factors influencing the overall survival of 78 MF-CCA patients

\begin{tabular}{|c|c|c|c|c|c|}
\hline \multirow[t]{2}{*}{ Factors } & \multicolumn{4}{|c|}{ Survival time (months) } & \multirow[t]{2}{*}{$P$} \\
\hline & Median & $95 \% \mathrm{Cl}$ of median & 3 years $(\%)$ & 5 years $(\%)$ & \\
\hline \multicolumn{6}{|l|}{ Sex } \\
\hline Male $(n=33)$ & 14.70 & $7.89-21.50$ & 21.2 & 18.2 & 0.719 \\
\hline Female $(n=45)$ & 10.82 & $5.85-15.79$ & 24.4 & 15.0 & \\
\hline \multicolumn{6}{|l|}{ Age } \\
\hline$\leqq 60(n=38)$ & 12.89 & $4.45-21.33$ & 26.3 & 21.1 & 0.505 \\
\hline$>60(n=40)$ & 12.99 & $7.23-18.74$ & 20.0 & 12.0 & \\
\hline \multicolumn{6}{|l|}{ Symptoms } \\
\hline Negative $(n=12)$ & 37.71 & $4.78-70.63$ & 58.3 & 41.7 & 0.006 \\
\hline Positive $(n=66)$ & 10.45 & $5.84-15.07$ & 16.7 & 11.9 & \\
\hline \multicolumn{6}{|l|}{ AST (IU/L) } \\
\hline$\leqq 34(n=39)$ & 13.32 & $9.53-17.10$ & 30.8 & 22.8 & 0.197 \\
\hline$>34(n=38)$ & 10.72 & $2.28-19.16$ & 15.8 & 10.5 & \\
\hline \multicolumn{6}{|l|}{ ALT (IU/L) } \\
\hline$\leqq 36(n=40)$ & 12.99 & $6.4 I-19.56$ & 25.0 & 19.7 & 0.625 \\
\hline$>36(n=3 I)$ & 14.70 & $7.8 I-21.58$ & 19.4 & 9.7 & \\
\hline \multicolumn{6}{|l|}{ ALP (IU/L) } \\
\hline$\leqq 94(n=23)$ & 23.90 & $11.65-36.15$ & 39.1 & 29.8 & 0.009 \\
\hline$>94(n=52)$ & 9.11 & $4.92-13.29$ & 15.4 & 5.0 & \\
\hline \multicolumn{6}{|l|}{ Bil (total) (mg/dL) } \\
\hline$\leqq 1.3(n=64)$ & 12.99 & $6.4 I-19.56$ & 25.0 & 16.9 & 0.581 \\
\hline$>1.3(n=14)$ & 10.72 & $0.00-22.23$ & 14.3 & 14.3 & \\
\hline \multicolumn{6}{|l|}{ Albumin (g/dL) } \\
\hline$\leqq 3.5(n=22)$ & 4.70 & $3.11-6.29$ & 18.2 & 13.6 & 0.063 \\
\hline$>3.5(n=49)$ & 19.04 & $|3.3|-24.76$ & 24.5 & 15.9 & \\
\hline \multicolumn{6}{|l|}{ Serum CEA (ng/dL) } \\
\hline$\leqq 5(n=25)$ & $|8.5|$ & $2.09-34.93$ & 40.0 & 27.0 & 0.043 \\
\hline$>5(n=31)$ & 10.29 & $4.05-16.53$ & 6.5 & 6.5 & \\
\hline \multicolumn{6}{|l|}{ Margin } \\
\hline Negative $(n=54)$ & 19.43 & $14.97-23.89$ & 33.3 & 23.8 & $<0.001$ \\
\hline Positive $(n=24)$ & 4.41 & $2.43-6.38$ & 0.0 & 0.0 & \\
\hline \multicolumn{6}{|l|}{ Size } \\
\hline$\leqq 5 \mathrm{~cm}(\mathrm{n}=32)$ & 19.99 & $13.75-26.23$ & 37.5 & 30.7 & 0.006 \\
\hline$>5 \mathrm{~cm}(\mathrm{n}=43)$ & 9.11 & $1.97-16.25$ & 14.0 & 7.0 & \\
\hline \multicolumn{6}{|l|}{ Lymph node } \\
\hline Negative $(n=47)$ & 19.89 & $16.7 \mid-23.07$ & 29.8 & 18.7 & 0.063 \\
\hline Positive $(n=29)$ & 10.45 & $0.00-22.71$ & 13.8 & 13.8 & \\
\hline \multicolumn{6}{|l|}{ Histology } \\
\hline Well $(n=2)$ & 2.73 & NA & 0.0 & 0.0 & 0.207 \\
\hline Moderate $(n=4 I)$ & 13.84 & $7.45-20.23$ & 22.0 & 17.1 & \\
\hline Poor $(n=33)$ & 12.99 & $5.25-20.72$ & 27.3 & 17.3 & \\
\hline Others $(n=2)$ & 4.37 & NA & 0.0 & 0.0 & \\
\hline \multicolumn{6}{|l|}{ SPARC expression } \\
\hline $\begin{array}{l}\text { Tumor positive and } \\
\text { stromal negative }(n=37)\end{array}$ & 17.16 & $9.21-25.12$ & 29.7 & 27.0 & 0.022 \\
\hline Others $(n=4 I)$ & 8.25 & $3.88-12.62$ & 17.1 & 6.5 & \\
\hline \multicolumn{6}{|l|}{ Post-op chemotherapy } \\
\hline Without $(n=33)$ & 5.65 & $2.47-8.84$ & 30.3 & 23.9 & 0.937 \\
\hline With $(n=45)$ & 14.70 & $9.64-19.75$ & 17.8 & II.I & \\
\hline \multicolumn{6}{|l|}{ Post-op radiotherapy } \\
\hline Without $(n=68)$ & 13.32 & $8.27-18.36$ & 26.5 & 18.9 & 0.071 \\
\hline With $(n=10)$ & 6.97 & $5.29-8.65$ & 0.0 & 0.0 & \\
\hline
\end{tabular}

Abbreviations: MF-CCA, mass-forming cholangiocarcinoma; AST, aspartate aminotransferase; IU, international unit; ALT, alanine aminotransferase; ALP, alkaline phosphatase; Bil, bilirubin; CEA, carcinoembryonic antigen; SPARC, secreted protein acidic and rich in cysteine; op, operation. 
Table 3 Cox proportional hazards analysis

\begin{tabular}{lll}
\hline Factors & Relative risk (95\% CI) & $\boldsymbol{P}$ \\
\hline Symptoms (positive/negative) & $1.973(0.8 \mathrm{II}-4.800)$ & 0.134 \\
ALP $(\leqq 94 \mathrm{~g} / \mathrm{dL} />94 \mathrm{~g} / \mathrm{dL})$ & $1.136(0.583-2.2 \mathrm{I})$ & 0.707 \\
Serum CEA $(\mathrm{ng} / \mathrm{dL})$ & $1.784(0.912-3.49 \mathrm{I})$ & $0.09 \mathrm{I}$ \\
Tumor size $(>5 \mathrm{~cm} / \leqq 5 \mathrm{~cm})$ & $1.64 \mathrm{I}(0.937-2.876)$ & 0.083 \\
Margin (positive/negative) & $2.574(1.336-4.959)$ & 0.005 \\
SPARC expression: tumor positive & $0.477(0.25 \mathrm{I}-0.906)$ & 0.024 \\
and stromal negative versus others & &
\end{tabular}

Abbreviations: ALP, alkaline phosphatase; CEA, carcinoembryonic antigen; SPARC, secreted protein acidic and rich in cysteine.

several cancers ${ }^{44}$ Interestingly, breast cancers revealed different epigenetic profiles of normal stromal fibroblasts and fibroblasts. ${ }^{45}$ Combined tumor- and host-derived factors are likely to initiate the activated fibroblast reaction to infiltrating carcinoma.

SPARC could be regarded as a potential anticancer target. Linolenic acid has been reported to regulate SPARC expression and secretion potentially. ${ }^{46}$ Tumor xenograft from cell lines harboring re-expressing SPARC restored sensitivity to fluorouracil and irinotecan and to radiation. ${ }^{47}$ Abraxane (Abraxis Oncology, Los Angeles, CA, USA) is an albumin-bound $130 \mathrm{~nm}$ particle form of paclitaxel, which may be dependent on SPARC expression for its uptake into cells. ${ }^{48-51}$ The prognostic impact of stromal behavior observed in our study implicated that there might be a necessity for searching therapeutic efforts that target not only tumor cells but also the juxtatumoral stroma cells that construct the surrounding microenvironment. As cancer cells undergo clonal evolution independently of stromal cells, the therapeutic targets of stromal cells will be different from those of cancer cells. Just as the success of compounds that target the tumor microenvironment such as bevacizumab and sunitinib, ${ }^{52-54}$ it is reasonable that agents, which target on the activated fibroblast component of the tumor microenvironment, may provide therapeutic effects.

However, many limitations should not be overlooked in this study. First, this is a retrospective study and SPARC expression is an arbitrary classification in these selected patients in this study. To verify the cutoff value of SPARC scoring in MF-CCA patients who had undergone curative hepatic resection, a prospective, randomized study is necessary. Second, to prevent from potential biases of immunohistochemistry quantification, standardized and reliable procedures are necessary to determine SPARC protein function and production.

Third, cancer stromal cells from nearly half of the subjects in our study had tested results of weak or absent SPARC expression, and even with 78 patients of CCA, our study was only moderately powered to distinguish survival status. Finally, it is unclear whether the poorer prognosis among patients with SPARC expressed in the CCA stroma is due to direct effect of SPARC expression or just reflection of an association between the expression of this protein and other aspects of CCA biology.
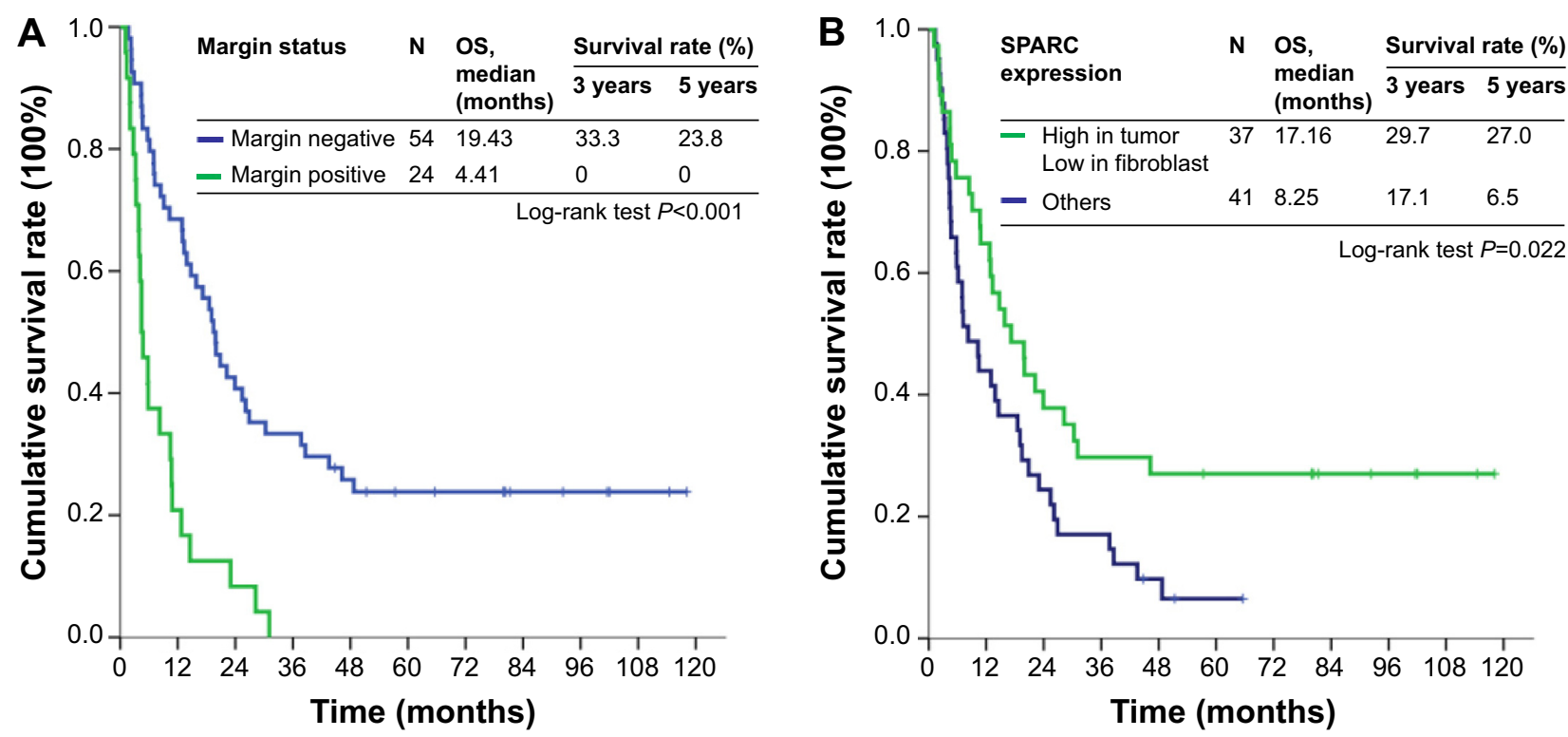

Figure 2 Comparison of OS rate of 78 MF-PCC patients who had undergone hepatectomy in relation to (A) resection margin and (B) SPARC staining result. Abbreviations: OS, overall survival; MF-PCC, mass-forming peripheral cholangiocarcinoma; SPARC, secreted protein acidic and rich in cysteine. 


\section{Conclusion}

In summary, stromal SPARC expression is a marker of poor prognosis, independent of common clinical parameters, including surgical margin status. The mechanisms that confer this malignant phenotype warrant further research.

\section{Acknowledgments}

This work was supported by Chang Gung Medical Research Program grants 3B0363 and CMRPG3B0533 to C-NY and by grants from the National Science Council (NMRPG5D6031 and MOST 103-2314-B-182A-081-MY2).

\section{Disclosure}

The authors report no conflicts of interest in this work.

\section{References}

1. Ustundag Y, Bayraktar Y. Cholangiocarcinoma: a compact review of the literature. World J Gastroenterol. 2008;14:6458-6466.

2. Khan SA, Thomas HC, Davidson BR, Taylor-Robinson SD. Cholangiocarcinoma. Lancet. 2005;366:1303-1314.

3. Patel T. Increasing incidence and mortality of primary intrahepatic cholangiocarcinoma in the United States. Hepatology. 2001;33:1353-1357.

4. Shaib Y, El-Serag HB. The epidemiology of cholangiocarcinoma. Semin Liver Dis. 2004;24:115-125.

5. Liver Cancer Study Group of Japan. Classification of Primary Liver Cancer. First English edition. Tokyo: Kanehara Press Co; 1997.

6. Weber SM, Jarnagin WR, Klimstra D, DeMatteo RP, Fong Y, Blumgart LH. Intrahepatic cholangiocarcinoma: resectability, recurrence pattern, and outcomes. J Am Coll Surg. 2001;193:384-391.

7. Razumilava N, Gores GJ. Cholangiocarcinoma. Lancet. 2014;383(9935): 2168-2179.

8. Uenishi T, Hirohashi K, Kubo S, et al. Histologic factors affecting prognosis following hepatectomy for intrahepatic cholangiocarcinoma. World J Surg. 2001;25:865-869.

9. Jarnagin WR, Fong Y, DeMatteo RP. Staging, resectability, and outcome in 225 patients with hilar cholangiocarcinoma. Ann Surg. 2001; 234:507-519.

10. de Groen PC, Gores GJ, LaRusso NF, et al. Biliary tract cancers. N Engl J Med. 1999;341:1368-1378.

11. Shirabe K, Shimada M, Harimoto N. Intrahepatic cholangiocarcinoma: its mode of spreading and therapeutic modalities. Surgery. 2002; 131:S159-S164

12. Bathe OF, Pacheco JT, Ossi PB. Management of hilar bile duct carcinoma. Hepatogastroenterology. 2001;48:1289-1294.

13. Utispan K, Thuwajit P, Abiko Y, et al. Gene expression profiling of cholangiocarcinoma-derived fibroblast reveals alterations related to tumor progression and indicates periostin as a poor prognostic marker. Mol Cancer. 2010;9:13.

14. Seol MA, Chu IS, Lee MJ, et al. Genome-wide expression patterns associated with oncogenesis and sarcomatous transdifferentation of cholangiocarcinoma. BMC Cancer. 2011;11:78.

15. Funk SE, Sage EH. The Ca2(+)-binding glycoprotein SPARC modulates cell cycle progression in bovine aortic endothelial cells. Proc Natl Acad Sci US A. 1991;88:2648-2652.

16. Kalluri R, Zeisberg M. Fibroblasts in cancer. Nat Rev Cancer. 2006;6: 392-401.

17. Puolakkainen PA, Brekken RA, Muneer S, Sage EH. Enhanced growth of pancreatic tumors in SPARC-null mice is associated with decreased deposition of extracellular matrix and reduced tumor cell apoptosis. Mol Cancer Res. 2004;2:215-224.
18. Brekken RA, Puolakkainen P, Graves DC, Workman G, Lubkin SR, Sage EH. Enhanced growth of tumors in SPARC null mice is associated with changes in the ECM. J Clin Invest. 2003;111:487-495.

19. Sato N, Fukushima N, Maehara N, et al. SPARC/osteonectin is a frequent target for aberrant methylation in pancreatic adenocarcinoma and a mediator of tumor-stromal interactions. Oncogene. 2003; 22:5021-5030

20. Yamashita K, Upadhay S, Mimori K, Inoue H, Mori M. Clinical significance of secreted protein acidic and rich in cysteine in esophageal carcinoma and its relation to carcinoma progression. Cancer. 2003;97:2412-2419.

21. Watkins G, Douglas-Jones A, Bryce R, Mansel RE, Jiang WG. Increased levels of SPARC (osteonectin) in human breast cancer tissues and its association with clinical outcomes. Prostaglandins Leukot Essent Fatty Acids. 2005;72:267-272.

22. Piao CQ, Liu L, Zhao YL, Balajee AS, Suzuki M, Hei TK. Immortalization of human small airway epithelial cells by ectopic expression of telomerase. Carcinogenesis. 2005;26:725-731.

23. Yamanaka M, Kanda K, Li NC, et al. Analysis of the gene expression of SPARC and its prognostic value for bladder cancer. J Urol. 2001; 166:2495-2499.

24. Uehara H, Nakaizumi A, Tatsuta M, et al. Diagnosis of pancreatic cancer by detecting telomerase activity in pancreatic juice: comparison with K-ras mutations. Am J Gastroenterol. 1999;94:2513-2518.

25. Jacob K, Webber M, Benayahu D, Kleinman HK. Osteonectin promotes prostate cancer cell migration and invasion: a possible mechanism for metastasis to bone. Cancer Res. 1999;59:4453-4457.

26. Briggs J, Chamboredon S, Castellazzi M, Kerry JA, Bos TJ. Transcriptional upregulation of SPARC, in response to c-Jun overexpression, contributes to increased motility and invasion of MCF7 breast cancer cells. Oncogene. 2002;21:7077-7091

27. Handrich SJ, Hough DM, Fletcher JG, Sarr MG. The natural history of the incidentally discovered small simple pancreatic cyst: long-term follow-up and clinical implications. AJR Am J Roentgenol. 2005; 184:20-23.

28. Wang CS, Lin KH, Chen SL, Chan YF, Hsueh S. Overexpression of SPARC gene in human gastric carcinoma and its clinic-pathologic significance. Br J Cancer. 2004;91:1924-1930.

29. Infante JR, Matsubayashi $H$, Sato N, et al. Peritumoral fibroblast SPARC expression and patient outcome with resectable pancreatic adenocarcinoma. J Clin Oncol. 2007;25(3):319-325.

30. Mantoni TS, Schendel RR, Rödel F, et al. Stromal SPARC expression and patient survival after chemoradiation for non-resectable pancreatic adenocarcinoma. Cancer Biol Ther. 2008;7(11):1806-1815.

31. Ohtsuka M, Ito H, Kimura F, et al. Results of surgical treatment for intrahepatic cholangiocarcinoma and clinicopathological factors influencing survival. Br J Surg. 2002;89(12):1525-1531.

32. Chen MF, Tsai HP, Jeng LB, et al. Prognostic factors after resection for hepatocellular carcinoma in noncirrhotic livers: univariate and multivariate analysis. World J Surg. 2003;27(4):443-447.

33. Yeh CN, Chen MF, Lee WC, Jeng LB. Prognostic factors of hepatic resection for hepatocellular carcinoma with cirrhosis: univariate and multivariate analysis. J Surg Oncol. 2002;81(4):195-202.

34. Yeh CN, Lee WC, Chen MF. Hepatic resection and prognosis for patients with hepatocellular carcinoma larger than $10 \mathrm{~cm}$ : two decades of experience at Chang Gung memorial hospital. Ann Surg Oncol. 2003; 10(9):1070-1076.

35. Klompje J, Petrelli NJ, Herrera L, Mittelman A. The prognostic value of preoperative alkaline phosphatase for resection of solitary liver metastasis from colorectal carcinoma. Eur J Surg Oncol. 1987;13(4): 345-347.

36. Chu K, Teele N, Dewey MW, Albright N, Dewey WC. Computerized video time lapse study of cell cycle delay and arrest, mitotic catastrophe, apoptosis and clonogenic survival in irradiated 14-3-3sigma and CDKN1A (p21) knockout cell lines. Radiat Res. 2004;162: $270-286$. 
37. Okabayashi T, Yamamoto J, Kosuge T, et al. The utility of CA19-9 in the diagnoses of cholangiocarcinoma in patients without primary sclerosing cholangitis. Am J Gastroenterol. 2000;95:204-207.

38. Chen MF. Peripheral cholangiocarcinoma (cholangiocellular carcinoma): clinical features, diagnosis and treatment. J Gastroenterol Hepatol. 1999;14:1144-1149.

39. Yeh CN, Jan YY, Yeh TS, Hwang TL, Chen MF. Hepatic resection of intraductal papillary type of cholangiocarcinoma. Ann Surg Oncol. 2004;11:606-611.

40. Levy MJ, Smyrk TC, Reddy RP, et al. Endoscopic ultrasound-guided trucut biopsy of the cyst wall for diagnosing cystic pancreatic tumors. Clin Gastroenterol Hepatol. 2005;3:974-979.

41. West RB, Nuyten DS, Subramanian S, et al. Determination of stromal signatures in breast carcinoma. PLoS Biol. 2005;3:e187.

42. Koukourakis MI, Giatromanolaki A, Brekken RA, et al. Enhanced expression of SPARC/osteonectin in the tumor-associated stroma of nonsmall cell lung cancer is correlated with markers of hypoxia/acidity and with poor prognosis of patients. Cancer Res. 2003;63:5376-5380.

43. Jones C, Mackay A, Grigoriadis A, et al. Expression profiling of purified normal human luminal and myoepithelial breast cells: identification of novel prognostic markers for breast cancer. Cancer Res. 2004; 64:3037-3045

44. Lindmark F, Zheng SL, Wiklund F, et al. H6D polymorphism in macrophage-inhibitory cytokine-1 gene associated with prostate cancer. J Natl Cancer Inst. 2004;96:1248-1254.

45. Hu M, Yao J, Cai L, et al. Distinct epigenetic changes in the stromal cells of breast cancers. Nat Genet. 2005;37:899-905.

46. Watkins G, Martin TA, Bryce R, Mansel RE, Jiang WG. Gammalinolenic acid regulates the expression and secretion of SPARC in human cancer cells. Prostaglandins Leukot Essent Fatty Acids. 2005;72: 273-278.
47. Tai IT, Dai M, Owen DA, Chen LB. Genome-wide expression analysis of therapy-resistant tumors reveals SPARC as a novel target for cancer therapy. J Clin Invest. 2005;115:1492-1502.

48. John TA, Vogel SM, Tiruppathi C, Malik AB, Minshall RD. Quantitative analysis of albumin uptake and transport in the rat microvessel endothelial monolayer. Am J Physiol Lung Cell Mol Physiol. 2003; 284:L187-L196.

49. Minshall RD, Sessa WC, Stan RV, et al. Caveolin regulation of endothelial function. Am J Physiol Lung Cell Mol Physiol. 2003;285: L1179-L1183.

50. Schnitzer JE, Oh P. Antibodies to SPARC inhibit albumin binding to SPARC, gp60, and microvascular endothelium. Am J Physiol Heart Circ Physiol. 1992;263:H1872-H1879.

51. Tiruppathi C, Finnegan A, Malik AB. Isolation and characterization of a cell surface albuminbinding protein from vascular endothelial cells. Proc Natl Acad Sci U S A. 1996;93:250-254.

52. Motzer RJ, Michaelson MD, Redman BG, et al. Activity of SU11248, a multitargeted inhibitor of vascular endothelial growth factor receptor and platelet-derived growth factor receptor, in patients with metastatic renal cell carcinoma. J Clin Oncol. 2006;24:16-24.

53. Hurwitz H, Fehrenbacher L, Novotny W, et al. Bevacizumab plus irinotecan, fluorouracil, and leucovorin for metastatic colorectal cancer. N Engl J Med. 2004;350:2335-2342.

54. Faivre L, Guardiola P, Lewis C, et al. Association of complementation group and mutation type with clinical outcome in fanconi anemia. European Fanconi Anemia Research Group. Blood. 2000;96: 4064-4070.
OncoTargets and Therapy

\section{Publish your work in this journal}

OncoTargets and Therapy is an international, peer-reviewed, open access journal focusing on the pathological basis of all cancers, potential targets for therapy and treatment protocols employed to improve the management of cancer patients. The journal also focuses on the impact of management programs and new therapeutic agents and protocols on

\section{Dovepress}

patient perspectives such as quality of life, adherence and satisfaction. The manuscript management system is completely online and includes a very quick and fair peer-review system, which is all easy to use. Visit http://www.dovepress.com/testimonials.php to read real quotes from published authors. 